\title{
Physical therapy practice patterns in acute exacerbations of chronic obstructive pulmonary disease
}

\author{
Leslie Harth MScPT, Jennifer Stuart MScPT, Catherine Montgomery MScPT, Karol Pintier MScPT, \\ Susan Czyzo MScPT, Kylie Hill PhD, Roger Goldstein MD, Dina Brooks PhD
}

\begin{abstract}
L Harth, J Stuart, C Montgomery, et al. Physical therapy practice patterns in acute exacerbations of chronic obstructive pulmonary disease. Can Respir J 2009;16(3):86-92.
\end{abstract}

BACKGROUND AND OBJECTIVE: The importance of the multidisciplinary approach to the management of chronic obstructive pulmonary disease is increasingly emphasized. The present study aimed to examine the current practice patterns of physical therapists involved in the management of patients hospitalized with an acute exacerbation of chronic obstructive pulmonary disease.

METHOD: A self-administered postal survey was distributed to the rehabilitation departments of all Canadian acute care hospitals with more than 250 beds. The survey addressed patient assessment, treatment, education and discharge planning for intensive care unit and/or ward admissions.

RESULTS: In total, 66\% of hospitals ( $\mathrm{n}=109)$ participated in the study, with provincial representation mainly from Ontario $(n=36$ [33\%]) and Quebec ( $n=36$ [33\%]). Assessment and treatment techniques did not differ greatly between the ward and the intensive care unit. Assessment focused on patient observation, pulse oximetry and auscultation, and was reported to be used 'always or frequently' by $76 \%, 76 \%$ and $69 \%$ of respondents, respectively. Less than $18 \%$ of respondents used a measure of functional capacity, and health-related quality of life measures were rarely used. Treatment focused on ambulatory techniques, with $78 \%$ and $75 \%$ of respondents using mobility and transfer training 'always or frequently', respectively. The most common educational topics were breathing exercises and positioning, which were addressed by $68 \%$ and $67 \%$ of respondents, respectively.

CONCLUSION: Patient assessment focused on physical impairments, with little use of measures of function or health-related quality of life, whereas treatment focused on mobility, with a lesser focus on airway clearance. Further study is needed to identify the factors that impact these practice patterns.

Key Words: Acute exacerbation; COPD; Physical therapy; Practice patterns; Survey

$\mathrm{C}$ hronic obstructive pulmonary disease (COPD) is the fourth leading cause of death in Canada (1), with at least 750,000 Canadians living with the disease (2). Individuals with moderate-to-severe COPD experience frequent episodes of transient worsening in health status during acute exacerbations (3). These acute exacerbations of COPD (AECOPD) are characterized by increased sputum volume and purulence, worsening shortness of breath (SOB), fatigue and mood disturbances. These changes contribute to a decrease in health-related quality of life (HRQL) and in daily physical activities (3-6).

\section{Modes d'intervention en physiothérapie pour les poussées aiguës de maladie pulmonaire obstructive chronique}

CONTEXTE ET OBJECTIF : On insiste de plus en plus sur l'importance de l'approche pluridisciplinaire dans la prise en charge de la maladie pulmonaire obstructive chronique. La présente étude visait à examiner les modes d'intervention en physiothérapie actuellement utilisés dans la prise en charge des patients hospitalisés pour des poussées aiguës de maladie pulmonaire obstructive chronique.

MÉTHODE : Un questionnaire postal auto-administré a été distribué aux services de réadaptation de tous les hôpitaux canadiens de soins aigus comptant plus de 250 lits. Le questionnaire portait sur l'évaluation des patients, les traitements, l'enseignement et la planification du congé après un séjour aux soins intensifs et/ou sur une unité de soins.

RÉSULTATS : En tout, 66 \% des hôpitaux $(\mathrm{n}=109)$ ont participé à l'étude, l'Ontario $(\mathrm{n}=36$ [33\%]) et le Québec $(\mathrm{n}=36$ [33\%]) étant les provinces les plus représentées. Les techniques d'examen et de traitement étaient assez semblables entre les unités de soins et les soins intensifs. L'évaluation portait sur l'observation du patient, l'oxymétrie pulsée et l'auscultation, qui, aux dires des répondants, étaient utilisées « toujours ou souvent », soit par $76 \%$, $76 \%$ et $69 \%$ d'entre eux, respectivement. Moins de $18 \%$ des répondants ont utilisé une mesure de capacité fonctionnelle, et peu ont dit recourir aux indices de qualité de vie liée à la santé. Le traitement était axé sur les techniques ambulatoires, $78 \%$ et $75 \%$ des répondants ayant affirmé donner « toujours ou souvent » un enseignement sur les techniques de mobilisation et de transfert, respectivement. L'enseignement au patient a surtout porté sur les exercices respiratoires et la posture, abordés par $68 \%$ et $67 \%$ des répondants, respectivement.

CONCLUSION : L'évaluation des patients a porté principalement sur les restrictions physiques, et peu de mesures fonctionnelles ou d'indices de qualité de vie liée à la santé ont été utilisés, tandis que le traitement a été axé sur la mobilisation, plutôt que sur la perméabilité des voies respiratoires. Il faudra approfondir la recherche pour identifier les facteurs qui influent sur les modes d'intervention.

Repeated exacerbations are a risk factor for increased mortality (7-9) and contribute to the health care burden associated with the disease, especially when they result in hospitalization (10). Therefore, an important goal for the management of patients with COPD is to minimize both the frequency and impact of acute exacerbations (10). Because COPD is increasingly recognized as a systemic disease, characterized by primary impairments of the respiratory system and secondary impairments including skeletal muscle dysfunction, the optimal management of these patients is best effected through a multidisciplinary 
approach, in which the skills of physicians, nurses, physical therapists and other health professionals are combined to optimize the function of the patient (10).

Recommended physical therapy management strategies for patients hospitalized with an AECOPD are unclear, reflecting the lack of well-designed studies to guide clinical decisionmaking. The few studies that examined the effectiveness of airway clearance techniques in this population have yielded mixed results $(11-17)$, likely attributed to methodological shortcomings in study methods including failure to recruit patients with copious bronchial secretions, lack of blinding of the outcome assessor to the aims of the study or to group allocation, infrequent use of appropriate outcome measures and inadequate comparisons with control group data.

In contrast, there is growing evidence to support pulmonary rehabilitation (PR) during or immediately after an AECOPD, including a recent meta-analysis (18) that demonstrated significant reductions in unplanned hospital admissions, as well as large improvements in exercise capacity and HRQL. These findings are contributing to the indication for expanding PR beyond patients who are clinically stable (19). Physical therapists, within the PR framework in Canada, play an integral role in prescribing, supervising and progressing whole body exercise training, and contribute importantly to disease-specific education and implementation of self-management strategies $(20,21)$.

To date, previously published systematic reviews and clinical guidelines regarding the management of patients hospitalized with an AECOPD have focused on medical management, with little attention directed at physical therapy-specific interventions $(3,22-25)$. Documenting current practice patterns is an important step in the development of best practice guidelines (26). Although Yohannes and Connelly (26) examined practice patterns of physical therapists in the United Kingdom in relation to airway clearance techniques for patients hospitalized with an AECOPD, such information is unavailable in most jurisdictions, including Canada. Therefore, we undertook a survey study that would enable us to describe the current practice patterns of Canadian physical therapists regarding the assessment, treatment, education and discharge planning for patients hospitalized with an AECOPD.

\section{Study design and protocol}

\section{METHODS}

Approval for the study was granted by the University of Toronto (Toronto, Ontario) Ethics Review Board. A prospective, cross-sectional postal survey was conducted across Canada between January and June 2007. Potential study sites were identified through the 2005 Canadian Health Facilities Directory (27) and defined as acute care general hospitals with more than 250 beds. For health care centres that comprised multiple sites, a separate questionnaire was mailed to each site. All facilities classified as being primary health care providers in pediatrics, developmental disabilities, psychiatry, long-term care, chronic care, rehabilitation or oncology were not considered eligible to participate in the present study.

Facilities that met the inclusion criteria were contacted by telephone to identify the name of the manager of rehabilitation services or physical therapy departments to whom a questionnaire, cover letter (in French and English) and preaddressed, postage-paid reply envelope was sent. Cover letters requested that the questionnaire be completed by the physical therapists predominantly involved in managing patients hospitalized with an AECOPD. The French version of the questionnaire was sent to all sites in Quebec and the English version was sent to all other sites. All facilities were given the option of receiving the questionnaire in either language. Consent was implied with the return of the completed questionnaire. Sites that did not wish to participate were encouraged to indicate their reason(s) and return the blank questionnaire. A modified Dillman approach (28) was used to optimize the response rate. Two weeks after the initial mailing, a reminder card was mailed, and three weeks after the reminder card, another package containing a replacement questionnaire and a reminder letter was mailed to sites that had not yet responded. On completion of the study, a thank you letter with a summary of the results was mailed to the participating sites.

\section{Survey instrument}

The survey was divided into three main sections. The first section required the respondents to indicate the frequency of use of specific assessment techniques, treatments and education topics. A five-point Likert scale that comprised the following responses was used: 'Always (91\% to 100\%)', 'Frequently (61\% to $90 \%)$ ', 'Sometimes (31\% to $60 \%)$ ', 'Rarely (1\% to $30 \%$ )' and 'Never $(0 \%)$ '. For the questions pertaining to the assessment and treatment of patients with an AECOPD, respondents were asked to consider their responses for admissions to the general ward separately from admissions to the intensive care unit (ICU). Questions regarding patient education and discharge planning pertained exclusively to ward-based admissions only. Respondents were also encouraged to indicate if a treatment technique or education regarding a specific topic was performed by health care practitioners other than physical therapists. The second section required the respondent to discuss discharge planning practices following admission for an AECOPD, and included questions regarding referrals to PR programs. The final section allowed for additional comments. To optimize its readability, the questionnaire was pilot tested by a physical therapist and a respirologist with current clinical expertise in the management of AECOPD. The responses of these individuals were excluded from the overall sample analysis.

\section{Statistical analysis}

Responses were numerically coded to allow for descriptive summaries and frequency analyses of the data using SPSS version 14.0 (SPSS, USA). Frequency variables regarding assessment, treatment and education were collapsed to create three responses; 'always and frequently', 'sometimes' and 'rarely and never'; all other questionnaire responses were analyzed in their original format.

\section{RESULTS}

\section{Response}

A total of 163 questionnaires were mailed to all 10 provinces: British Columbia $(n=16)$, Alberta $(n=9)$, Saskatchewan $(n=3)$, Manitoba $(n=7)$, Ontario $(n=54)$, Quebec $(n=55)$, New Brunswick $(n=8)$, Nova Scotia $(n=6)$, Prince Edward Island $(n=1)$ and Newfoundland $(n=4)$. A total of 109 questionnaires were returned, yielding a response rate of $66 \%$. Of the 


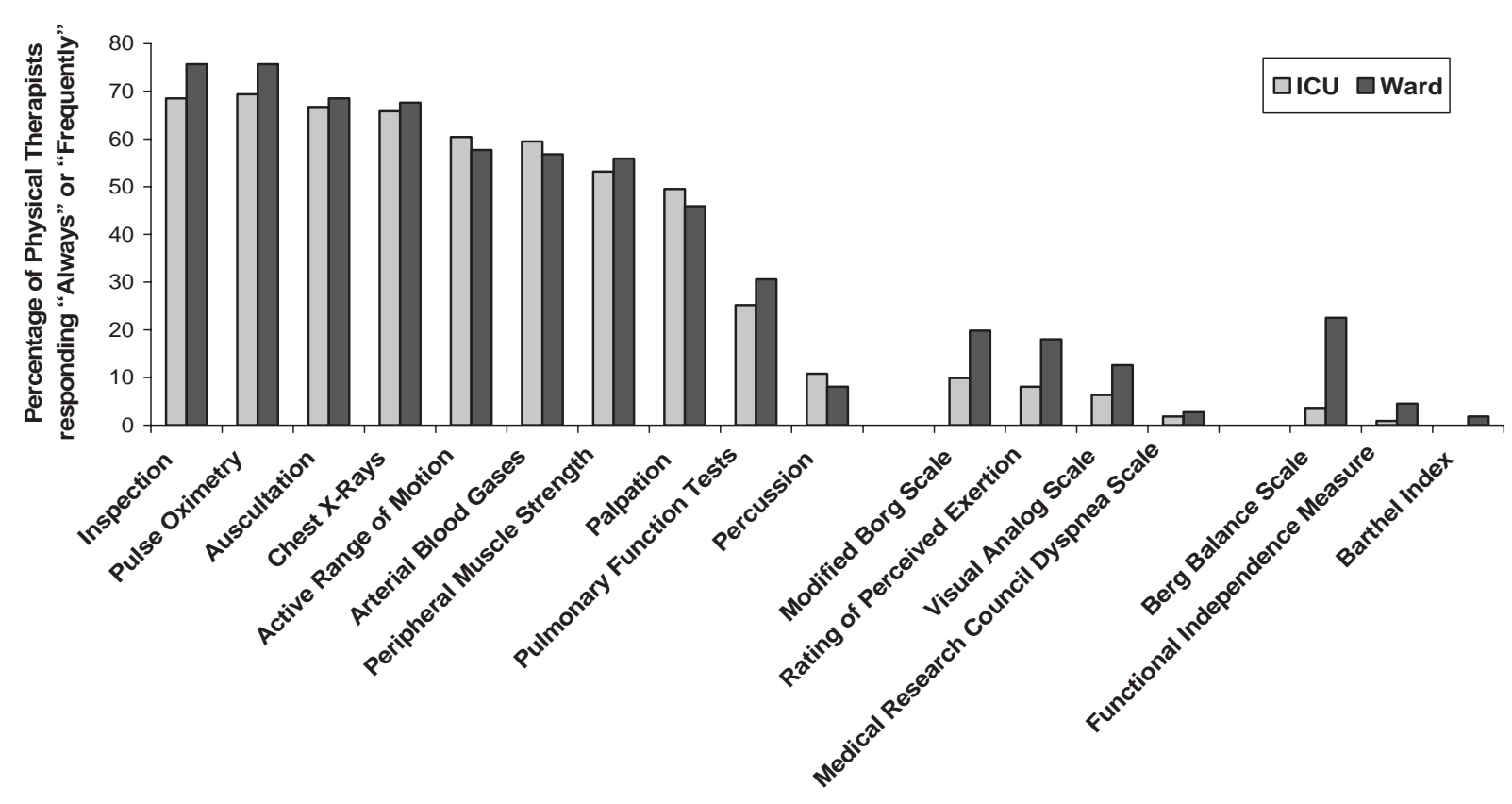

Assessment Measures

Figure 1) Assessment measures of patients with an acute exacerbation of chronic obstructive pulmonary disease on the ward and in the intesive care unit. The $y$-axis indicates the percentage of physical therapists who reported the frequency of use of a particular assessment technique on the ward and in the ICU as 'always (91\% to 100\%)' or 'frequently (61\% to 90\%)'. The x-axis indicates the assessment technique used

respondents, $80 \%(\mathrm{n}=87)$ agreed to take part in the study, $6 \%$ $(n=7)$ declined to participate and $14 \%(n=15)$ reported that they did not treat patients hospitalized with an AECOPD. The majority of respondents were from Ontario and Quebec, each constituting $32 \%(n=36)$ of the total sample, with the remaining respondents from British Columbia $(\mathrm{n}=12$ [11\%]), New Brunswick $(n=7[6 \%])$, Alberta $(n=6[6 \%])$, Manitoba $(n=6[6 \%])$, Saskatchewan $(n=3[3 \%])$, Nova Scotia $(n=3 \quad[3 \%])$ and Newfoundland $(n=2[2 \%])$.

\section{Assessment}

The frequency with which assessment strategies, such as measures of respiratory or physical impairments, dyspnea and function were used 'always or frequently' by the respondents on the ward and in the ICU are summarized in Figure 1. Assessment techniques used 'always or frequently' on the ward by greater than $65 \%$ of respondents comprised patient observation $(\mathrm{n}=84[76 \%])$, pulse oximetry $(\mathrm{n}=84[76 \%])$, auscultation $(n=76[69 \%])$ and chest radiography $(n=75[68 \%])$. Objective measures of dyspnea, such as the Medical Research Council Dyspnea Scale (29), were used 'always or frequently' by less than $25 \%$ of respondents. Similarly, less than $24 \%$ of respondents used objective measures of function 'always or frequently', including a standardized measures of balance (Berg Balance Scale [30]); $\mathrm{n}=25[23 \%]$ ) or independence with activities of daily living and mobility (Barthel Index [31]; $n=5$ [5\%] and Functional Independence Measure [32]; $\mathrm{n}=2$ [2\%]). Measures of functional exercise capacity were used 'always or frequently' by less than $17 \%$ of respondents, with measures such as the 6 min walk test (33) used 'always or frequently' by $16 \%(n=18)$ of respondents. More than $85 \%$ of respondents $(n=87)$ indicated that they 'rarely or never' used HRQL measures.
Specifically, the Short Form-36 (34), Chronic Respiratory Questionnaire (35) and St George Respiratory Questionnaire (36) were used 'rarely or never' by 79\% ( $\mathrm{n}=87)$ of respondents, while the Hospital Anxiety Depression Scale (37) was 'rarely or never' used by $78 \%$ of respondents $(n=86)$.

For patients admitted to an ICU with an AECOPD, the assessment techniques used 'always or frequently' by more than $65 \%$ of respondents included patient observation $(n=76$ [69\%]), auscultation $(\mathrm{n}=74[67 \%])$, pulse oximetry $(\mathrm{n}=77[69 \%])$ and chest radiographs $(n=73[66 \%])$. Respondents indicated that objective measures of dyspnea were used 'always or frequently' by less than $10 \%$ of respondents. Measures of function, such as the Berg Balance Scale and Functional Independence Measure, were used 'always or frequently' by less than $4 \%(n=4)$ and $1 \%$ $(\mathrm{n}=1)$, respectively, of physical therapists involved in the management of patients admitted to an ICU.

\section{Treatment}

The frequency with which individual treatment techniques were used by the respondents both on the ward and in the ICU are summarized in Figure 2. In ward-based admissions, the treatment strategies used 'always or frequently' by more than $70 \%$ of respondents comprised pursed lip breathing $(n=80[72 \%])$, walking $(n=87[78 \%])$, transfer training $(n=83[75 \%])$ and bed mobility exercises $(n=86[78 \%])$. Airway clearance techniques were applied 'always or frequently' by less than one-half of the respondents. Approximately one-half of the respondents performed strength training exercises 'always or frequently', with lower limb and upper limb resistance exercises prescribed by $57 \%(n=63)$ and $43 \%(n=48)$ of respondents, respectively.

In the ICU, the treatment strategies used 'always or frequently' by more than $50 \%$ of respondents included bed 


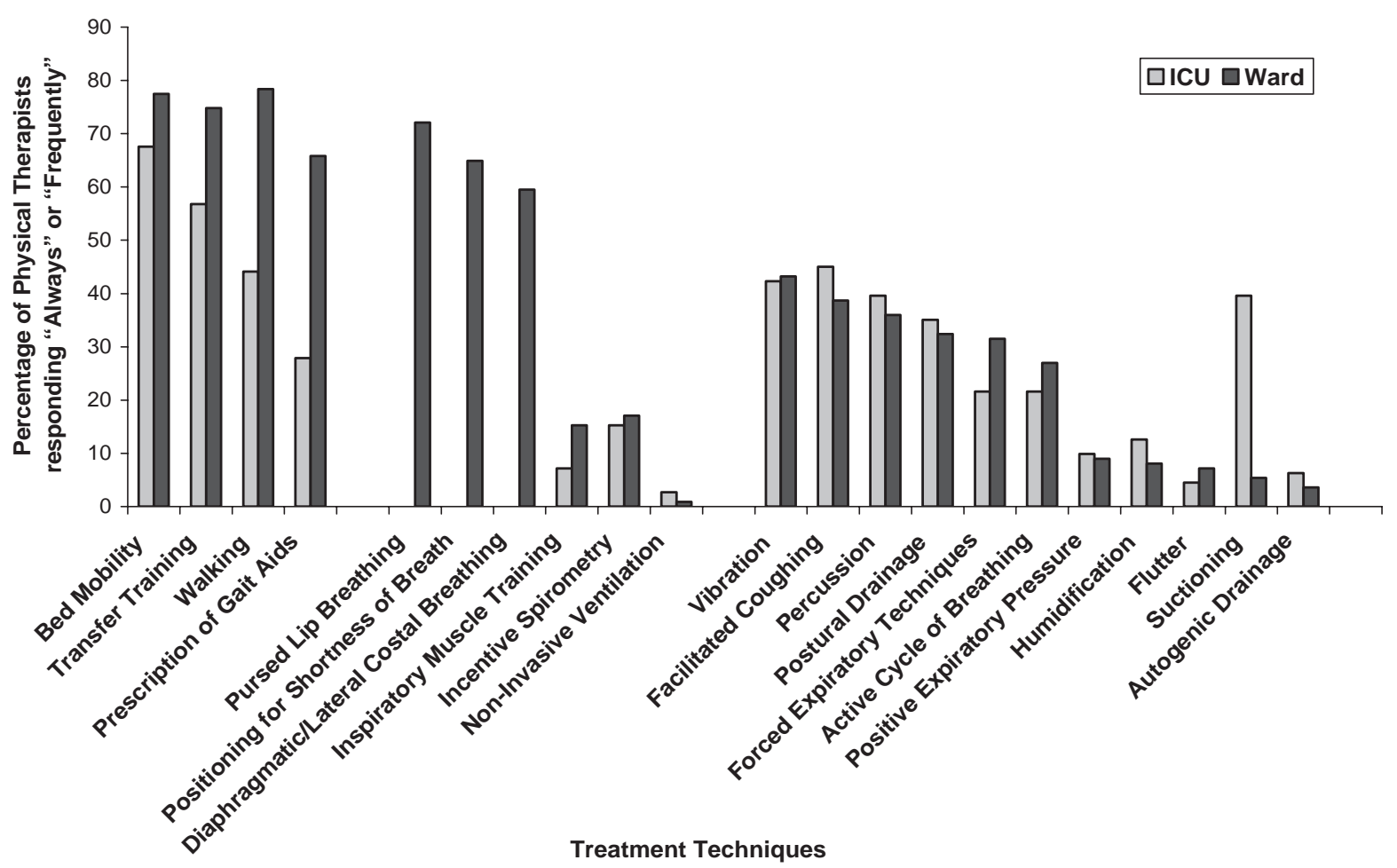

Figure 2) Treatment techniques of patients admitted to a hospital ward or intensive care unit with an acute exacerbation of chronic obstructive pulmonary disease. The $y$-axis indicates the percentage of physical therapists who reported the frequency of use of a particular treatment technique on the ward and in the intensive care unit as 'always (91\% to 100\%)' or 'frequently (61\% to 90\%)'. The $x$-axis indicates the treatment techniques used

mobility ( $n=75[68 \%])$ and transfer training ( $n=63$ [57\%]). Airway clearance techniques were used 'always or frequently' by less than $50 \%$ of respondents, with vibration $(n=47[42 \%])$ and facilitated coughing $(n=50$ [45\%]) being the most commonly used techniques.

\section{Education}

As presented in Figure 3, more than one-half of respondents indicated that they 'always or frequently' educated their patients regarding breathing exercises $(n=75[68 \%])$, positioning for SOB $(n=74[67 \%])$, airway clearance techniques $(n=64[58 \%])$, strategies for dyspnea relief $(n=63$ [57\%]), energy conservation $(n=60[54 \%])$ and whole-body exercise $(n=57$ [51\%]). Topics discussed 'always or frequently' by less than $6 \%$ of respondents included correct inhaler techniques $(n=6[5 \%])$, flight travel $(n=5[5 \%])$, medications $(n=3[3 \%])$ and end-of-life decision making $(n=2[2 \%])$. Topics discussed by other (nonphysical therapy) health care professionals included medication use $(n=68$ [61\%]), use of inhalers ( $n=61$ [55\%]), end-of-life decision making $(n=60[54 \%])$ and smoking cessation $(n=16[14 \%])$.

\section{Discharge planning}

More than one-half of respondents $(n=61$ [55\%]) indicated that less than one-quarter of patients were referred to PR following discharge from hospital for an AECOPD. The remaining respondents indicated that their referral rate to PR ranged from one-half of all patients $(n=18[16 \%])$ to three-quarters of all patients $(n=5[5 \%])$. Referrals to PR were primarily initiated by physical therapists $(n=37$ [33\%]) and medical staff $(n=20[18 \%])$. The time period between referral and commencement of PR ranged from 'less than 2 weeks' ( $n=6$ [5\%]) to 'greater than 8 weeks' $(n=19[17 \%])$. The primary reason cited for delay of PR commencement was wait lists.

\section{DISCUSSION}

The present article is the first report on practice patterns among Canadian physical therapists managing patients hospitalized with an AECOPD. The novel findings are:

1. Physical therapists generally used similar assessment and treatment techniques for patients, regardless of whether they were admitted to the ward or the ICU;

2. Assessment predominantly focused on respiratory impairments such as general patient observation, auscultation, pulse oximetry and chest radiography (formal quantitative measures of dyspnea, independence with activities of daily living, exercise capacity and HRQL were rarely collected);

3. Physical therapy treatments most often comprised patient mobilization, with airway clearance techniques and specific peripheral muscle strength training used by only one-half of respondents;

4. Physical therapists frequently educated patients regarding the use of breathing strategies, such as pursed lip breathing and diaphragmatic breathing, as well as positioning for SOB; and

5. Referral rates to PR following an AECOPD were low, with the majority $(55 \%)$ of hospitals referring less than $25 \%$ of their patients to such programs. 


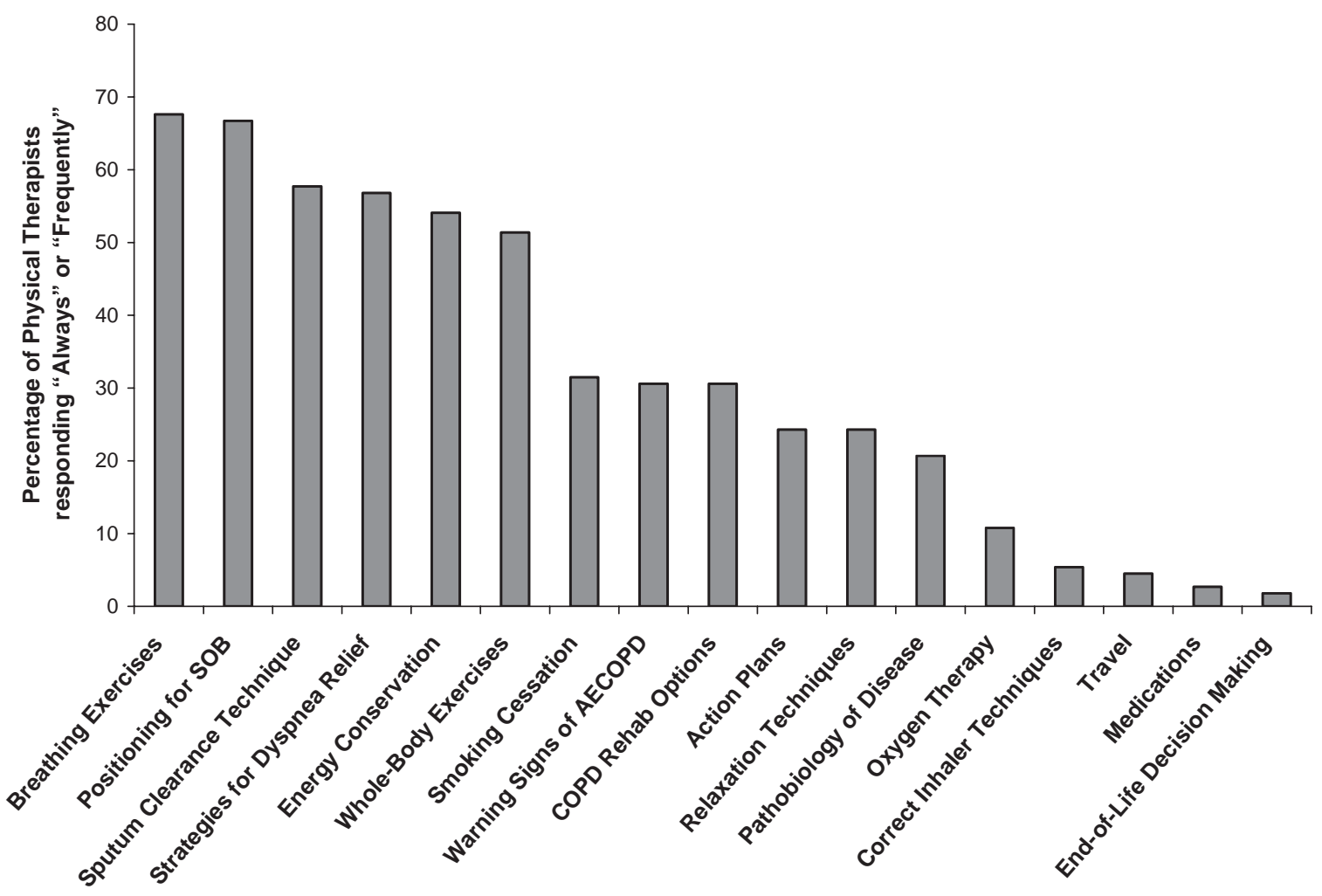

Education Topics

Figure 3) Education of patients with an acute exacerbation of chronic obstructive pulmonary disease (AECOPD) on the ward and in the intensive care unit. The $y$-axis indicates the percentage of physical therapists who 'always (91\% to 100\%)' or 'frequently (61\% to 90\%)' discussed a particular topic on the ward or in the intensive care unit. The $x$-axis indicates the education topics. Rehab Rehabilitation; SOB Shortness of breath

The physical therapy assessments were mainly comprised of observing the patient's general appearance, auscultation, pulse oximetry and chest radiographs. This focus on identifying acute pulmonary impairments is consistent with the way in which the pathophysiology of an AECOPD influences airway inflammation, sputum characteristics and gas exchange $(10,38)$. Despite these assessment techniques, specific airway clearance techniques were used 'always or frequently' by fewer than $50 \%$ of respondents. This finding suggests that the majority of patients hospitalized with an AECOPD may not require assistance to clear their secretions.

Formal quantitative measures of independence with activities of daily living, exercise capacity, HRQL and dyspnea were rarely included in the assessment of patients despite poor functional exercise capacity. Impaired HRQL and dyspnea were identified as risk factors associated with hospital readmission in $\operatorname{COPD}(6,39,40)$. While an informal assessment of these variables may be performed on a daily basis, the use of formal quantitative assessments (eg, Medical Research Council Dyspnea Scale, St George Respiratory Questionnaire, 6 min walk test) especially before discharge would assist in identifying individuals at greatest risk for readmission, which would serve to help select those who might benefit from an urgent referral to a PR program $(4,5)$. Furthermore, when preparing for discharge, a 6 min walk test may be useful in establishing the need for mobility aids because patients who walk less than $300 \mathrm{~m}$ have been reported (41) to increase functional exercise capacity and reduce dyspnea on exertion through the use of a wheeled walker.
A very small number of physical therapists included anxiety or depression as part of their clinical assessment, despite the fact that an AECOPD will heighten mood disturbances (5) because increased feelings of anxiety and depression are risk factors for readmission to hospital (42). Simple screening questionnaires implemented before discharge such as the Hospital Anxiety and Depression Scale (43) or the Primary Care Evaluation of Mental Disorders (44), would assist in identifying patients with psychological impairments and allow for timely referral to the most appropriate mental health professional.

Physical therapy treatments focused on early mobilization and exercise training. Such programs, administered during or immediately following an AECOPD are feasible, well-tolerated $(45,46)$ and effective at increasing exercise capacity, improving HRQL and reducing the use of health care resources (18). Kirsten et al (45) described a corridor-based walking program for patients hospitalized with an AECOPD in which patients performed a 6 min walk test on a treadmill each day and were then supervised during a daily corridor walk, with the goal of covering at least $75 \%$ of their most recent 6 min walk test distance. Compared with a control group that received the usual medical care, this structured yet simple exercise program was effective at increasing functional exercise capacity and reducing dyspnea during submaximal exercise.

Lower limb strength training exercises - used 'always or frequently' by $57 \%$ of respondents for ward-based admissions may help minimize the loss of peripheral muscle mass known to occur during such clinical events (47). Compared with 
aerobic- or endurance-based exercise training such as a walking program, specific strength-based training elicits a lower ventilatory load (48) and, therefore, is more likely to be tolerated by patients who describe an increase in their dyspnea during an AECOPD.

Despite the frequent use of exercise and strength training, less than $25 \%$ of patients were referred to PR on discharge. Whether this is an awareness issue, an availability issue or a resource issue was not the subject of the survey, but the results were consistent with a previous PR survey in which only $1.2 \%$ of Canadians had access to a PR program (21).

In addition to exercise training, breathing strategies such as pursed lip breathing and diaphragmatic breathing were frequently taught, despite the relatively limited evidence that these techniques influence breathing patterns or the sensation of dyspnea $(49,50)$.

It was not surprising that assessment focused on the degree of pulmonary impairment, whereas treatment addressed mobility and functional independence. During the few first days of a hospital admission, when symptoms are the most severe, the physical therapists prioritize the assessment of gas exchange and airway clearance. At this point, patients have very limited tolerance to even the assessment of functional exercise capacity or peripheral muscle strength. As symptoms improve, the focus shifts to optimizing functional independence in preparation for discharge. Practice guidelines require a standardized approach to establish the most useful intensity for exercise training and for evaluating the effectiveness of exercise during hospitalization. This is not currently possible, given the low use of timed walk tests or other measures of exercise capacity in the present study.

Smoking cessation was discussed infrequently by physical therapists or other members of the health care team, despite evidence that even brief interventions influence smoking cessation and that the latter has a marked effect on the rate of decline of airway function (51-53). It is possible that the small number of health care workers providing education regarding the importance of smoking cessation is the result, in part, from a large percentage of COPD patients that have already abstained from smoking. However, this contention remains speculative. Regardless of the reason for our finding, it is important to note that the Canadian Thoracic Society's recommendations for management of COPD state that smoking

\section{REFERENCES}

1. Canadian Institute for Health Information, Canadian Lung Association, Health Canada, Statistics Canada. Respiratory Disease in Canada. 2001.

2. Lacasse Y, Brooks D, Goldstein RS. Trends in the epidemiology of chronic obstructive pulmonary disease in Canada, 1980-1995. Chest 1999;116:306-3.

3. Bach PB, Brown C, Gelfard SE, McCroy DC. Management of acute exacerbations of chronic obstructive pulmonary disease: A summary and appraisal of published evidence. Chest 2001;119:600-20.

4. Carr JH, Goldstein R, Brooks D. Acute exacerbations of COPD in subjects completing pulmonary rehabilitation. Chest 2007;132:127-34.

5. Costi S, Brooks D, Goldstein RS. Perspectives that influence action plans for chronic obstructive pulmonary disease. Can Respir J 2006; 13:362-8.

6. Pitta F, Troosters T, Probst VS, Spruit MA, Decramer ML, Gosselink R. Physical activity and hospitalization for exacerbation of COPD. Chest 2006;129:536-44.

7. Connors AFJ, Dawson NV, Thomas C, et al. Outcomes following acute exacerbation of severe chronic obstructive lung disease. The cessation is the single most important intervention for patients experiencing an increase in severity of symptoms and disability (10). Therefore, education regarding smoking cessation or the importance of sustained abstinence should be regarded as a priority for physical therapists and other members of the multidisciplinary team involved in the management of patients hospitalized with an AECOPD.

The generalizability of the present study was limited because of a response rate of $66 \%$, and the lack of participation from Prince Edward Island and the Territories. Nevertheless, the results describe current practice among physical therapists and point to areas in which additional evidence is required before best practice guidelines can be established for physical therapists managing patients admitted with an AECOPD.

\section{CONCLUSION}

Practice patterns of physical therapists involved in managing patients hospitalized with an AECOPD were similar whether the patient was admitted to a ward or the ICU. Assessments focused predominantly on acute impairments of pulmonary function, and treatment focused predominantly on patient mobilization and breathing techniques aimed at minimizing dyspnea. Discordance between assessment and treatment techniques may relate to the lack of pre-existing guidelines for management of an AECOPD as well as the evolving clinical situation over the duration of the admission. Further research is needed to identify factors responsible for influencing the practice patterns of physical therapists. It is possible that the use of team-based standardized assessments in this population would promote a coordinated and comprehensive management approach from all members of the multidisciplinary team. Furthermore, professional development within physical therapy should promote evidence to support the use and application of different assessment and treatment strategies.

ACKNOWLEDGEMENTS: This research was completed in partial fulfillment of the requirements for the MScPT degree at the University of Toronto, Toronto, Ontario. The authors acknowledge Laura Cook, Debbie Sutton, Cathy Evans, Cheryl Cott and Kim Chao for their assistance in this research, and the pilot testers for their input on the questionnaire. This research was funded by The Canadian Lung Association.

SUPPORT investigators (Study to Understand Prognoses and Preferences for Outcome and Risk of Treatment). Am J Respir Crit Care Med 1996;154:959-67.

8. Groenewegen KH, Schols AMWJ, Wouters EFM. Mortality and mortality-related factors after hospitalization for acute exacerbation of COPD. Chest 2003;124:459-67.

9. Seneff MG, Wagner DP, Wagner RP, Zimmerman JE, Knaus WA. Hospital and 1-year survival of patients admitted to intensive care units with acute exacerbation of chronic obstructive pulmonary disease. JAMA 1995;274:1852-7.

10. O'Donnell DE, Aaron S, Bourbeau J, et al. Canadian Thoracic Society recommendations for management of chronic obstructive pulmonary disease - 2007 update. Can Respir J 2007;14 Suppl B:5B-32B.

11. Vargas F, Bui HN, Boyer A, et al. Intrapulmonary percussive ventilation in acute exacerbations of COPD patients with mild respiratory acidosis: A randomized controlled trial. Crit Care 2005;9:R 382-9.

12. Wollmer P, Ursing K, Midgren B, Eriksson L. Inefficiency of chest percussion in the physical therapy of chronic bronchitis. Eur J Respir Dis 1985;66:233-9.

13. Brown PM, Manfreda J, McCarthy DS, et al. The effect of 
mechanical vibration in patients with acute exacerbations of chronic obstructive pulmonary disease. Physiother Can 1987;39:371-4.

14. Bellone A, Lascioli R, Raschi S, Guzzi L, Adone R. Chest physical therapy in patients with acute exacerbation of chronic bronchitis: Effectiveness of three methods. Arch Phys Med Rehabil 2000;81:558-60.

15. Antonaglia V, Lucangelo U, Zin WA, et al. Intrapulmonary percussive ventilation improves the outcome of patients with acuteexacerbation of chronic obstructive pulmonary disease using a helmet. Crit Care Med 2006;34:2940-5.

16. Buscaglia AJ, St. Marie MS. Oxygen saturation during chest physiotherapy for acute exacerbation of severe chronic obstructive pulmonary disease. Respir Care 1983;28:1009-13.

17. Bellone A, Spagnolatti L, Massobrio M, et al. Short-term effects of expiration under positive pressure in patients with acute exacerbation of chronic obstructive pulmonary disease and mild acidosis requiring non-invasive positive pressure ventilation. Intensive Care Med 2002;28:581-5.

18. Puhan MA, Scharplatz M, Troosters T, Steurer J. Respiratory rehabilitation after acute exacerbation of COPD may reduce risk for readmission and mortality - a systematic review. Respir Res 2005;6:54-65.

19. Lacasse Y, Goldstein R, Lasserson T, Martin S. Pulmonary rehabilitation for chronic obstructive pulmonary disease. Cochrane Database of Syst Rev 2006:CD003793.

20. Brooks D, Lacasse Y, Goldstein RS. Pulmonary rehabilitation programs in Canada: national survey. Can Respir J 1999;6:55-63.

21. Brooks D, Sottana R, Bell B, et al. Characterization of pulmonary rehabilitation programs in Canada 2005. Can Respir J 2007;14:87-92.

22. Snow V, Lascher S, Mottur-Pilson C. Evidence base for management of acute exacerbations of chronic obstructive pulmonary disease. Ann Intern Med 2001;134:595-9.

23. McCrory DC, Brown C, Gelfand SE, et al. Management of acute exacerbation of COPD: A summary and appraisal of published evidence. Chest 2001;119:1190-1209.

24. Soto FJ, Varkey B. Evidence-based approach to acute exacerbations of COPD. Curr Opin Pulm Med 2003;9:117-24.

25. Hurst JR, Wedzicha JA. Chronic obstructive pulmonary disease: The clinical management of an acute exacerbation. Postgrad Med J 2004;80:497-505.

26. Yohannes AM, Connolly MJ. A national survey: Percussion, vibration, shaking and active cycle breathing techniques used in patients with acute exacerbations of chronic obstructive pulmonary disease. Physiotherapy 2007;93:110-3.

27. Canadian Health Facilities Directory, 2005. 7th edn. Toronto: Southam Communications Ltd, 2005.

28. Dillman D. Mail and internet surveys: The Tailored Design Method, 2nd edn. Toronto: John Wiley \& Sons Inc, 2000.

29. Mahler DA, Wells CK. Evaluation of clinical methods for rating dyspnea. Chest 1988;93:580-6.

30. Berg K, Wood-Dauphinee S, Williams JI, Gayton D. Measuring balance in the elderly: Preliminary development of an instrument. Physiother Can 1989;41:304-11.

31. Mahoney FI, Barthel D. Functional evaluation: The Barthel Index. Maryland State Med J 1965;14:56-61.

32. Wright, J. The FIM(TM). The Center for Outcome Measurement in Brain Injury. <www.tbims.org/combi/FIM 2000 (Version current at June 4, 2008).

33. Enright PL, McBurnie MA, Bittner V, et al. The 6 minute walk test: A quick measure of functional status in elderly adults. Chest 2003;123:387-98.
34. Ware JJ, Sherbourne CD. The MOS 36-item short-form health survey (SF-36). I. Conceptual framework and item selection. Medical Care 1992;30:473-83.

35. Guyatt GH, Berman LB, Townsend M, Puglsey SO, Chambers LW. A measure of quality of life for clinical trials in chronic lung disease. Thorax 1987;42:773-8.

36. Jones PW, Quirk FH, Baveystock CM. The St. George's Respiratory Questionnaire. Resp Med 1991;85(Suppl):25-31.

37. Zigmond AS, Snaith RP. The Hospital Anxiety And Depression Scale. Acta Psychiatr Scand 1983:67:361-70.

38. Hunter MH and King DE. COPD: Management of acute exacerbations and chronic stable disease. Am Fam Physician 2001;64:603-12,621-2.

39. Cao Z, Ong KC, Eng P, Tan WC, Ng TP. Frequent hospital readmissions for acute exacerbation of COPD and their associated factors. Respir 2006;11:188-95.

40. Almagro P, Barreiro B, Ochoa de Echaguen A, et al. Risk factors for hospital readmission in patients with chronic obstructive pulmonary disease. Respiration 2006;73:311-7.

41. Solway S, Brooks D, Lau L, Goldstein R. The short-term effects of a rollator on functional exercise capacity among individuals with severe COPD. Chest 2002;122:56-65.

42. Gudmundsson G, Gislason T, Janson C et al. Risk factors for rehospitalisation in COPD: Role of health status, anxiety and depression. Eur Respir J 2005;26:414-9.

43. Dowson C, Laing R, Barraclough $\mathrm{R}$ et al. The use of the Hospital Anxiety and Depression Scale (HADS) in patients with chronic obstructive pulmonary disease: A pilot study. N Z Med J 2001;114:447-9.

44. Spitzer RL, Kroenke K, Williams JB. Validation and utility of a selfreport version of PRIME-MD: The PHQ primary care study. Primary Care Evaluation of Mental Disorders. Patient Health Questionnaire. JAMA 1999;282:1737-44.

45. Kirsten DK, Taube C, Lehnigk B, Jorres RA, Magnussen H. Exercise training improves recovery in patients with COPD after an acute exacerbation. Respir Med 1998;92:1191-8.

46. Man WD, Polkey MI, Donaldson N, Gray BJ, Moxham J. Community pulmonary rehabilitation after hospitalization for acute exacerbation of chronic obstructive pulmonary diseas: Randomized controlled study. BMJ 2004;329:1209-14.

47. Spruit MA. Enhanced physiotherapy management of acute exacerbations of chronic obstructive pulmonary disease. Chron Respir Dis 2005;2:117-9.

48. Troosters T, Casaburi R, Gosselink R, Decramer M. Pulmonary rehabilitation in chronic obstructive pulmonary disease. Am J Respir Crit Care Med 2005;172:19-38.

49. Spahija J, de Marchiw M, Grassino A. Effects of imposed pursed-lips breathing on respiratory mechanics and dyspnea at rest and during exercise in COPD. Chest 2005;128:640-50.

50. Gosselink R. Diaphragmatic breathing reduces efficiency of breathing in patients with chronic obstructive pulmonary disease. Am J Respir Crit Care Med 1995;151:1136-42.

51. Fletcher C, Peto R. The natural history of chronic airflow obstruction. Br Med J 1977:1:1645-8.

52. Kanner RE, Anthonisen NR, Connett JE. Lower respiratory illness promotes $\mathrm{FEV}_{1}$ decline in current smokers but not ex-smokers with mild chronic obstructive pulmonary disease. Am J Respir Crit Care Med 2001;164:358-64.

53. Anthonisen NR, Skeans MA, Wise RA, et al. The effects of a smoking cessation intervention on 14.5-year mortality: A randomized clinical trial. Ann Intern Med 2005;142:233-9. 


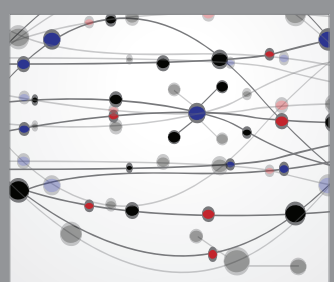

The Scientific World Journal
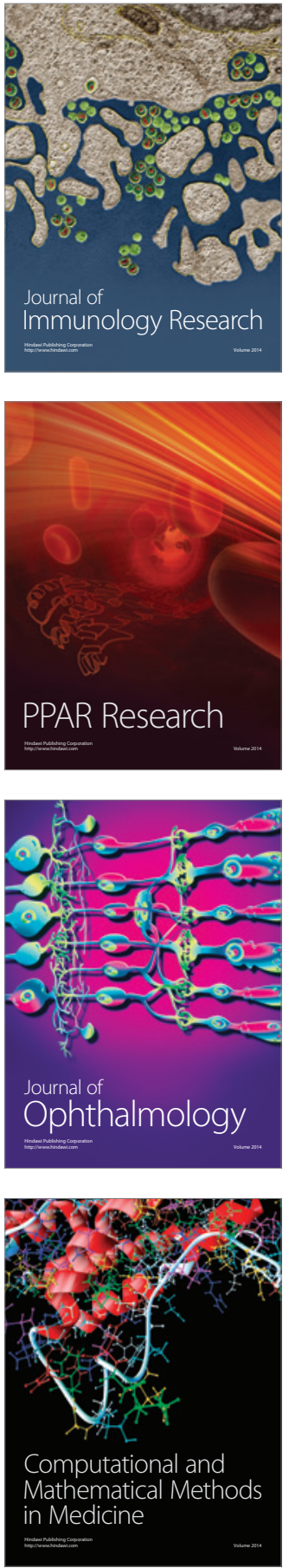

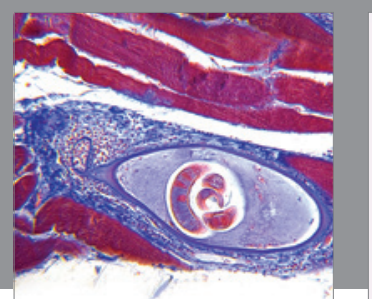

Gastroenterology Research and Practice

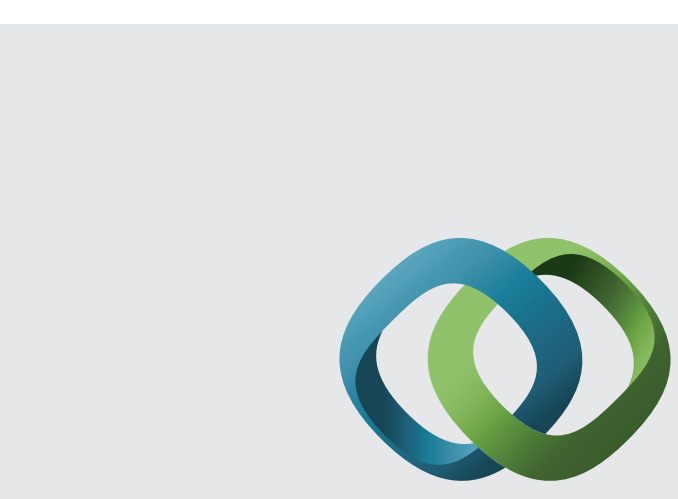

\section{Hindawi}

Submit your manuscripts at

http://www.hindawi.com
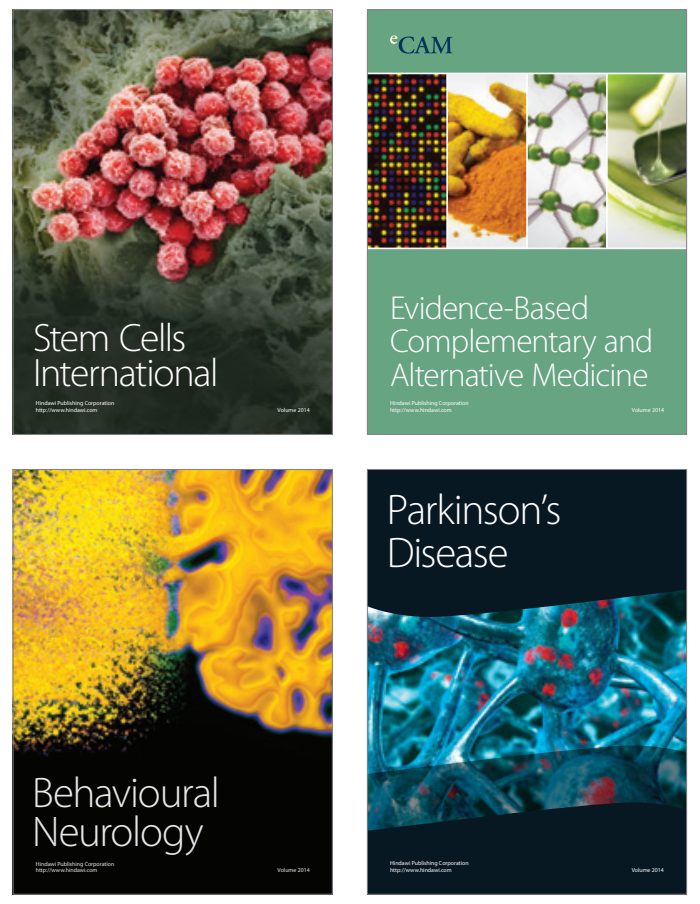
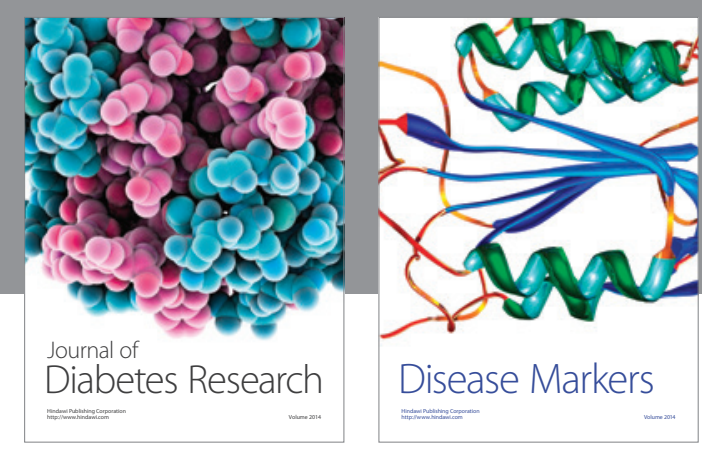

Disease Markers
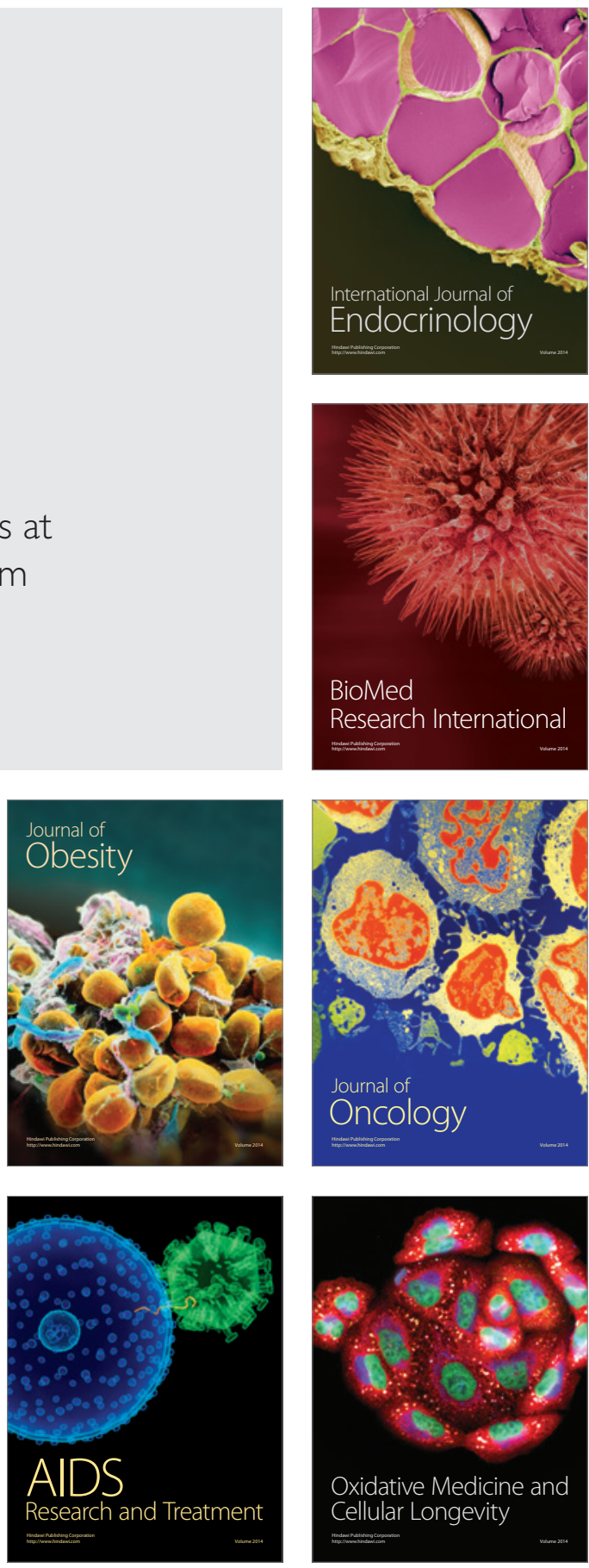